\title{
A comparative study of respiratory syncytial virus (RSV) prophylaxis in premature infants within the Canadian Registry of Palivizumab (CARESS)
}

\author{
B. Paes $\cdot$ I. Mitchell • A. Li • K. L. Lanctôt • \\ The CARESS Investigators
}

Received: 17 February 2012 / Accepted: 27 March 2012 / Published online: 1 May 2012

(C) The Author(s) 2012. This article is published with open access at Springerlink.com

\begin{abstract}
We examined the dosing regimens, compliance, and outcomes of premature infants who received palivizumab within the Canadian Registry of Palivizumab (CARESS). Infants receiving $\geq 1$ dose of palivizumab during the 20062011 respiratory syncytial virus (RSV) seasons were recruited across 30 sites. Respiratory illness events were captured monthly. Infants $\leq 32$ completed weeks gestational age (GA) (Group 1) were compared to 33-35 completed weeks GA infants (Group 2) following prophylaxis. In total, 6,654 patients were analyzed (Group 1, $n=5,183$; Group 2, $n=1,471$ ). The mean GA was $29.9 \pm 2.9$ versus $34.2 \pm 2.2$ weeks for Groups 1 and 2, respectively. Group differences were significant (all $p$-values $<0.05$ ) for the following: proportion of males, Caucasians, siblings, multiple births, maternal smoking, smoking
\end{abstract}

The CARESS Investigators (corporate author): U. Allen, G. Bacheyie, A. Bayliss, C. Bjornson, M. Blayney, A.-M. Canakis, R. Canning, G. Caouette, K. Chang, L. Chang, A. Chiu, B. DiGravio, J.P. Doray, M.E. Dumas, V. Ho, C. Hui, F. Jagdis, M. Lebel, D. Lee, C. Majaesic, I. Margolis, M. Mitchell, K. O’Brien, C. Ojah, A. Papageorgiou, J. Popovich, K. Sankaran, B. Simmons, D. Stinson.

\section{B. Paes}

Department of Pediatrics, McMaster University,

Hamilton, Ontario, Canada

\section{Mitchell}

Department of Pediatrics, University of Calgary,

Calgary, Alberta, Canada

A. Li $\cdot$ K. L. Lanctôt

Medical Outcomes and Research in Economics (MORE $\left.{ }^{\circledR}\right)$

Research Group, Sunnybrook Health Sciences Centre,

University of Toronto,

Toronto, Ontario, Canada

\section{K. L. Lanctôt $(\bowtie)$}

Sunnybrook Health Sciences Centre, 2075 Bayview Avenue, Room FG-05,

Toronto, Ontario M4N 3 M5, Canada

e-mail: krista.lanctot@sunnybrook.ca during pregnancy, household smokers, $>5$ household individuals, birth weight, and enrolment age. Overall, infants received $92.6 \%$ of expected injections. Group 1 received significantly more injections, but a greater proportion of Group 2 received injections within recommended intervals. The hospitalization rates were similar for Groups 1 and 2 for respiratory illness ( $4.7 \%$ vs. $3.7 \%, p=0.1)$ and $\operatorname{RSV}(1.5 \%$ vs. $1.4 \%, p=0.3)$. Neither the time to first respiratory illness [hazard ratio $=0.9,95$ $\%$ confidence interval (CI) $0.7-1.2, p=0.5$ ] nor to first RSV hospitalization (hazard ratio $=1.3,95 \%$ CI $0.8-2.2, p=0.3$ ) were different. Compliance with RSV prophylaxis is high. Despite the higher number of palivizumab doses in infants $\leq 32$ completed weeks GA, the two groups' respiratory illness and RSV-positive hospitalization rates were similar.

\section{Introduction}

Respiratory syncytial virus (RSV) is an important viral respiratory pathogen in children in terms of individual morbidity and societal costs. The majority of children aged $<2$ years have experienced an RSV-related illness, predominantly during the winter months, but in some countries, RSV exposure prevails throughout the entire year.

Palivizumab is a humanized monoclonal antibody indicated for RSV prophylaxis in infants and children at high risk, and has been shown to be safe and well tolerated [1].

The Canadian Paediatric Society and most international pediatric position statements support prophylaxis for all infants of $\leq 32$ completed weeks gestational age (GA) [2-8]. Infants of 33-35 completed weeks GA comprise a significant proportion of the annual birth cohort, and prophylaxis for this group of infants is currently based on a composite of risk factors or the use of validated risk factor models that specifically target infants at moderate to high risk for severe RSV infection and hospitalization [9-15]. In Canada, prophylaxis is recommended 
provincially for moderate- to high-risk 33-35 completed weeks GA infants with the use of a risk scoring tool [7, 12].

Infants of 33-35 completed weeks GA have previously been shown to have similar RSV-positive hospitalization rates and incur morbidities and costs not indifferent to those infants of $\leq 32$ completed weeks GA [16-18]. There are limited data systematically comparing the effects of prophylaxis on the outcomes of infants in specific gestational age cohorts, following RSV-related hospitalization. The collection of longterm data on seasonality, risk factors, and outcomes is necessary in order to evaluate the impact of prophylaxis in everyday practice and examine hospitalization rates in similar premature populations globally.

The Canadian Registry of Palivizumab (CARESS) is a drug registry that prospectively collects information on patient demographics, including risk factors for RSV, palivizumab usage, characteristics of each hospitalization for both respiratory illness and RSV-positive respiratory infections, and compliance in any patient receiving palivizumab. In addition, safety data on serious adverse events possibly related to palivizumab are collected. The primary objective of the present paper is to compare data on premature infants without pre-existing medical disorders of $\leq 32$ completed weeks GA (Group 1) to that of infants of 33-35 completed weeks GA (Group 2) within CARESS.

\section{Methods}

Any pediatric patient receiving at least one dose of palivizumab in any RSV season from 2006 to 2011 was eligible for inclusion [19]. Children were excluded if a parent or legal guardian could not communicate in either English or French, or if the child had received palivizumab as part of a clinical trial during the study period. Only premature infants without underlying medical disorders such as bronchopulmonary dysplasia (BPD), congenital heart disease (CHD), neuromuscular impairments, cystic fibrosis (CF), dysmorphologic syndromes, chromosomal anomalies, and inherited disorders were included in this analysis. This maintained comparability of the assembled cohorts by avoiding potential confounding by known risk factors that could increase the risk of RSV hospitalization. Group 1 infants were $\leq 32$ completed weeks GA, while Group 2 comprised infants of 33-35 completed weeks GA. Group 2 infants qualified for prophylaxis if they were considered moderate to high risk for RSV infection and hospitalization. [12].

Subjects were enrolled by the treating physician and/or research nurse. Following consent, baseline data were obtained on patient demographics, prior medical history, neonatal course, and details of current palivizumab administration. Follow-up telephone interviews were conducted monthly until the end of the RSV season, obtaining data on palivizumab administration, changes in baseline data, and specific information regarding respiratory infections.
In the event of a hospitalization, and with parental consent, the relevant hospital records were reviewed by the site's research nurse for detailed information on the criteria for hospitalization, length of stay [regular ward vs. intensive care unit (ICU)], days on respiratory support and/or intubation, and type of RSV test performed and diagnosis, as reported in the hospital discharge summary. The study was approved by the research ethics board of each participating institution.

SPSS version 19.0 (SPSS Inc., Chicago, IL, USA) was utilized to analyze data by standard descriptive methods, comparative statistics [chi-square, analysis of variance (ANOVA), and $t$-tests] and regression analysis. Premature infants of $\leq 32$ completed weeks GA (Group 1) were compared to infants of 33-35 completed weeks GA (Group 2). A $p$-value of less than 0.05 was considered to be significant. The primary endpoint was the time to first RSV-positive hospitalization. A Cox proportional hazards analysis was conducted to determine the effect of group on the time to first respiratory illness hospitalization and the time to first RSV-positive hospitalization, as well as to examine the effects of any potential covariates to be determined a priori.

\section{Results}

Subjects

Subjects were enrolled between October 2006 and May 2011. A total of 10,092 infants were recruited in 30 geographically located Canadian sites: five from Western Canada (British Columbia, Alberta, Manitoba, or Saskatchewan), 22 from Central Canada (Ontario, Quebec), and three from Eastern Canada (New Brunswick, Newfoundland, Nova Scotia, or Prince Edward Island). Of the 10,092 patients, 6,654 were included in the analysis, with 5,183 subjects categorized into Group 1 and 1,471 into Group 2. The demographic and neonatal information of the infants is displayed in Table 1. The average $[ \pm$ standard deviation (SD) $]$ GA in Group 1 was $29.9 \pm 2.9$ weeks, and it was $34.2 \pm 2.2$ weeks in Group 2 . There were significant differences between the groups in almost all demographic categories. Group 2 had a greater proportion of males, a greater proportion with siblings, multiple births, a mother who smokes, a mother who smoked during pregnancy, any smokers in the household, $\geq 2$ smokers in the household, $>5$ individuals in the household, and, on average, the infants weighed more at birth (Table 1). Group 1 infants were more likely to be Caucasian, and, on average, were older at enrolment (Table 1). Infants in Group 1 had more complicated neonatal courses, with a greater percentage requiring respiratory support and oxygen therapy. Group 1 infants also spent a longer length of time on respiratory support and oxygen therapy. Finally, a greater proportion of Group 1 infants had documented necrotizing enterocolitis, 
Table 1 Demographic and neonatal information

Group 1 ( $\leq 32$ weeks GA), $n=5,183$ Group 2 (33-35 weeks GA), $n=1,471 p$-value

\begin{tabular}{|c|c|c|c|}
\hline \multicolumn{4}{|l|}{ Demographic information } \\
\hline Mean gestational age (weeks $\pm \mathrm{SD}$ ) & $29.9 \pm 2.9$ & $34.2 \pm 2.2$ & $<0.0005$ \\
\hline No. of males $(\%)$ & $2,837(54.7)$ & $937(63.7)$ & $<0.0005$ \\
\hline No. of Caucasians (\%) & $3,634(70.1)$ & $980(66.6)$ & 0.011 \\
\hline Mean age at enrolment (months \pm SD) & $3.7 \pm 2.9$ & $2.3 \pm 2.8$ & $<0.0005$ \\
\hline Mean birth weight $(g \pm S D)$ & $1,430 \pm 577$ & $2,150 \pm 507$ & $<0.0005$ \\
\hline No. in daycare $(\%)$ & $48(0.9)$ & $33(2.2)$ & $<0.0005$ \\
\hline No. with siblings (\%) & $2,897(55.9)$ & $1,146(77.9)$ & $<0.0005$ \\
\hline No. of multiple births (\%) & $1,795(34.6)$ & $575(39.1)$ & 0.002 \\
\hline No. with mother that smokes (\%) & $720(13.9)$ & $242(16.5)$ & 0.012 \\
\hline No. with mother that smoked during pregnancy (\%) & $698(13.5)$ & $235(16.0)$ & 0.015 \\
\hline No. with any smokers in the household (\%) & $1,378(26.6)$ & $493(33.5)$ & $<0.0005$ \\
\hline No. with $\geq 2$ smokers at home (\%) & $524(10.1)$ & $218(14.8)$ & $<0.0005$ \\
\hline No. with $>5$ individuals in the household (\%) & $1,093(21.1)$ & $641(43.6)$ & $<0.0005$ \\
\hline No. with a history of atopy in the immediate family (\%) & $2,027(39.1)$ & $562(38.2)$ & 0.545 \\
\hline \multicolumn{4}{|l|}{ Neonatal information } \\
\hline Mean length of stay (days \pm SD) & $54.4 \pm 42.9$ & $21.1 \pm 37.4$ & $<0.0005$ \\
\hline No. with respiratory support (\%) & $3,795(73.2)$ & $414(28.1)$ & $<0.0005$ \\
\hline Mean length of respiratory support (days $\pm \mathrm{SD}$ ) & $19.3 \pm 24.8$ & $3.8 \pm 5.9$ & $<0.0005$ \\
\hline No. with oxygen therapy (\%) & $3,119(60.1)$ & $356(24.2)$ & $<0.0005$ \\
\hline Mean length of oxygen therapy (days $\pm \mathrm{SD}$ ) & $26.3 \pm 39.6$ & $6.2 \pm 13.4$ & $<0.0005$ \\
\hline No. with documented necrotizing enterocolitis (\%) & $215(4.1)$ & $15(1.0)$ & $<0.0005$ \\
\hline No. with surgery for patent ductus arteriosus (\%) & $242(4.7)$ & $6(0.4)$ & $<0.0005$ \\
\hline No. with documented sepsis (\%) & 908 (17.5) & $57(3.8)$ & $<0.0005$ \\
\hline
\end{tabular}

surgery for patent ductus arteriosus, and documented sepsis. This is in keeping with their mean lower GA.

\section{Utilization}

A total of 26,540 injections were administered overall. An average of $4.0 \pm 1.6$ injections was given to each infant in any single RSV season. Group 1 infants, on average, received a greater number of injections in a season than Group 2 infants $(4.1 \pm 1.6$ vs. $3.7 \pm 1.5, p<0.0005)$.

\section{Compliance}

We defined compliance in two ways: expected number of doses versus actual number received, and inter-dose interval. For the expected number of doses, the calculation assumed monthly injections from the first dose to the end of the RSV season [11]. Overall, infants in both groups received 92.6 $27.9 \%$ of the expected number of injections. Groups 1 and 2 received similar percentages of their expected injections (92.9 $\pm 27.9 \%$ vs. $91.6 \pm 27.9 \%, p=0.12$ ).

For the number of days between injections, intervals of $30 \pm 5$ days were considered to be compliant. However, an interval of $20 \pm 4$ days between the first and second injections likely results in higher trough levels after the first dose, potentially offering better RSV protection. Therefore, an interval of 16-35 days between the first and second injections was considered to be compliant

A greater proportion of Group 2 infants received their appropriate dose-interval injections than Group 1 (75.7\% vs. $71.9 \%, p=0.003)$.

Respiratory illness and RSV-positive hospitalizations

RSV-positive hospitalizations and associated morbidities are shown in Table 2. Apart from the mean age at the time of admission to hospital, there were no differences evident between the groups. The RSV-positive hospitalization rate was calculated follows:

RSV - positive hospitalization rate

$$
\begin{aligned}
= & \frac{\text { No. hospitalized for respiratory illness }}{\text { Total no. of children }} \\
& \times \frac{\text { No. of RSV }- \text { positive children }}{\text { Total no. of children tested }}
\end{aligned}
$$


Table 2 Respiratory syncytial virus (RSV)-positive hospitalizations

\begin{tabular}{llll}
\hline & $\begin{array}{l}\text { Group 1 }(\leq 32 \text { weeks } \\
\text { GA }), n=62\end{array}$ & $\begin{array}{l}\text { Group 2 }(33-35 \text { weeks } \\
\text { GA }), n=18\end{array}$ & $p$-value \\
\hline Mean age at admission (months $\pm \mathrm{SD})$ & $4.9 \pm 2.8$ & $2.8 \pm 2.5$ & 0.004 \\
Mean length of stay (days $\pm \mathrm{SD})$ & $6.7 \pm 5.4$ & $5.2 \pm 5.0$ & 0.276 \\
No. requiring intubation (\%) & $4(6.5)$ & $1(5.6)$ & 1.000 \\
Mean length of intubation (days $\pm \mathrm{SD})$ & $0.5 \pm 2.2$ & $0.2 \pm 0.9$ & 0.556 \\
No. requiring respiratory support (\%) & $14(22.6)$ & $4(22.2)$ & 1.000 \\
Mean length of respiratory support (days $\pm \mathrm{SD})$ & $1.3 \pm 2.9$ & $0.3 \pm 1.8$ & 0.184 \\
No. admitted to ICU (\%) & $16(25.8)$ & $5(27.8)$ & 1.000 \\
Mean length of ICU stay (days $\pm \mathrm{SD})$ & $1.2 \pm 2.7$ & $1.3 \pm 2.4$ & 0.906 \\
\hline
\end{tabular}

Overall, 297 infants were hospitalized 339 times for respiratory illnesses, giving a hospitalization incidence rate of $4.5 \%$. Of these, 243 were tested for RSV, and 80 were positive, giving an overall RSV-positive hospitalization rate of $1.47 \%$. Groups 1 and 2 did not have significantly different hospitalization rates for respiratory-related events (4.7\% vs. $3.7 \%, p=0.1)$ nor RSV-positive infections $(1.5 \%$ vs. $1.4 \%, p=0.3$ ). Group allocation (Group 1 vs. Group 2) also did not have a significant effect on the time to first hospitalization [hazard ratio $=0.9,95 \%$ confidence interval (CI) $0.7-1.2, p=0.5]$ nor on the time to first RSV-positive hospitalization (hazard ratio $=1.3,95 \%$ CI $0.8-2.2, p=0.3$ ) (Fig. 1).

Table 3 describes the demographic differences between infants who were hospitalized with an RSV infection and those who were either not hospitalized or who had a nonRSV-positive hospitalization. A greater proportion of hospitalized infants had siblings, a mother who smokes, smokers at home, $>5$ individuals in the household, and a history of atopy in the immediate family. A Cox proportional hazards analysis found that each of these risk factors independently had a significant effect on the time to first RSVpositive hospitalization (siblings: hazard ratio $=2.5,95 \%$ CI $1.3-4.8, p=0.004 ;>5$ individuals in the household: hazard ratio $=2.1,95 \%$ CI 1.8-3.3, $p=0.003$; history of atopy: hazard ratio $=2.3,95 \% \mathrm{CI} 1.4-3.7, p=0.001$; smokers: hazard ratio $=1.7,95 \%$ CI 1.0-2.6, $p=0.035)$. Interestingly, cumulative risk factors in an individual infant significantly increased the hazard ratio (Fig. 2), from 4.3 (95\% CI 1.018.8) with one risk factor to 24.3 (95\% CI 5.1-114.6) with four risk factors. However, the Cox proportional hazards analysis showed no effect of group allocation $(p=0.640)$, even when the number of risk factors are taken into consideration (model: chi-square $=47.21, \mathrm{df}=2, p<0.0005$ ).

\section{Discussion}

RSV-related hospitalization rates for premature infants of $\leq 35$ weeks GA range from 11 to $28 \%$ [20-25] and are not indifferent across the gestational age group strata. Boyce et al., in a retrospective Tennessee Medicaid study, reported that infants of $<28$ weeks, 29-32 weeks, and 33-35 weeks GA compared to healthy term enrollees had RSV hospitalizations per 1,000 child years of the RSV season of 187.5, 163.6, and 159.6 versus 88.2, respectively [21]. Similarly, Heikkinen et al. determined RSV hospitalizations in preterm infants $<2$ years of age from 1991-2000 and documented an incidence of $7 \%$ in those who were $<28$ weeks GA ( $n=$ $168), 7 \%$ in $29-32$ weeks GA $(n=498)$, and $4 \%$ in premature infants 33-35 weeks GA $(n=1,133)$ [26]. Apnea may be a marker of RSV disease severity in young infants [27, 28 , but the risk could not be quantified in a systematic review [29]. Schiller et al. noted that, of 31 preterm infants admitted to the pediatric ICU between 2004 and 2007, the incidence of central apnea ranged from 3.2\% ( $<28$ weeks GA) to $32.3 \%$ (28-32 weeks GA) and 64.5\% (33-36 weeks GA) [30]. Additionally, data on morbidities and outcomes in 33-35 weeks GA infants following an RSV illness indicate that they are similar or worse than those born at $\leq 32$ weeks in terms of rates of apnea, intubation, ventilation, oxygen supplementation, systemic complications, ICU admission, hospital and ICU length of stay, and median costs for patient care [16-18]. In a matched-control study of 32-35 weeks GA infants hospitalized with RSV, follow-up healthcare resource utilization up to a mean of 2.1 years of age was significantly higher in index cases, with a higher incidence of overall accompanying mortality and sudden or unexplained death [31]. Following hospitalization of $32-$ 35 weeks GA infants with RSV, parents' health-related quality of life is also significantly impacted, with more and longer time off work for child care, excess workload related to infant illness, and burden associated with lower scores in physical activities of daily living [32]. Fatalities for hospitalized premature infants across 36 published studies (1966-2009) are between 0 and $6.1 \%$ [33] and low birth weight $<2,500 \mathrm{~g}$ is an independent risk factor for mortality from bronchiolitis [34].

The safety and efficacy of RSV prophylaxis in the reduction of RSV hospitalizations has been demonstrated in a 
Fig. 1 Cox proportional hazard curves depicting the effect of group allocation on the time to hospitalization for respiratory illness (a) and respiratory syncytial virus (RSV)-positive infection (b), comparing infants of $\leq 32$ completed weeks gestational age (GA; solid lines) and those of 33-35 completed weeks GA (dotted lines).

Group allocation did not have an effect in either case [respiratory illness: hazard ratio $=0.9,95 \%$ confidence interval (CI) $0.70-1.2, p=0.5$; RSV-positive infection: hazard ratio $=1.3,95 \% \mathrm{CI}$ $0.8-2.2, p=0.3$ ]
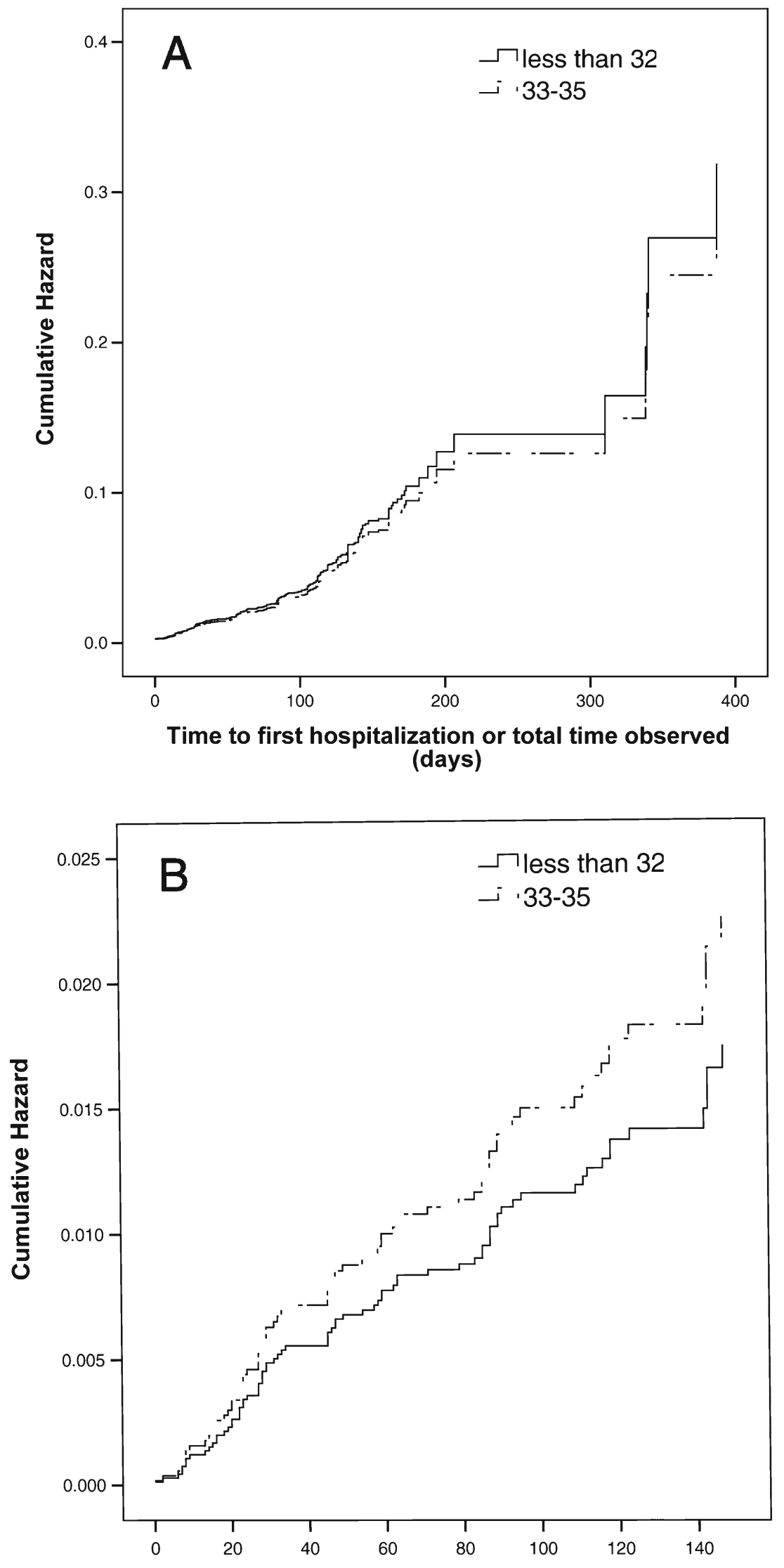

Time to first RSV-positive hospitalization or total time observed (days) 
Table 3 Demographic and neonatal information for patients who were and were not hospitalized for an RSV infection

RSV-positive hospitalization, $n=80 \quad$ Non-RSV-positive hospitalization $\quad p$-value or not hospitalized, $n=6,574$

\begin{tabular}{|c|c|c|c|}
\hline \multicolumn{4}{|l|}{ Demographic information } \\
\hline Mean gestational age (weeks \pm SD) & $30.5 \pm 3.2$ & $30.9 \pm 3.3$ & 0.260 \\
\hline No. of males $(\%)$ & $42(52.5)$ & $3,732(56.8)$ & 0.429 \\
\hline No. of Caucasians (\%) & $60(75.0)$ & $4,554(69.3)$ & 0.329 \\
\hline Mean age at enrolment (months $\pm \mathrm{SD}$ ) & $3.0 \pm 2.0$ & $3.4 \pm 2.9$ & 0.259 \\
\hline Mean birth weight $(g \pm \mathrm{SD})$ & $1,598 \pm 957$ & $1,589 \pm 631$ & 0.901 \\
\hline No. in daycare $(\%)$ & $0(0)$ & $81(1.2)$ & 0.628 \\
\hline No. with siblings (\%) & $66(82.5)$ & $3,977(60.5)$ & $<0.0005$ \\
\hline No. of multiple births (\%) & $34(42.5)$ & $2,336(35.5)$ & 0.198 \\
\hline No. with mother that smokes (\%) & $19(23.8)$ & $944(14.4)$ & 0.023 \\
\hline No. with mother that smoked during pregnancy (\%) & $17(21.3)$ & $916(13.9)$ & 0.074 \\
\hline No. with smokers in the household (\%) & $32(40.0)$ & $1,839(28.0)$ & 0.024 \\
\hline No. with $\geq 2$ smokers at home (\%) & $13(16.3)$ & $729(11.1)$ & 0.151 \\
\hline No. with $>5$ individuals in the household (\%) & $35(43.8)$ & $1,699(25.8)$ & 0.001 \\
\hline No. with a history of atopy in the immediate family (\%) & $48(60.0)$ & $2,541(38.7)$ & $<0.0005$ \\
\hline \multicolumn{4}{|l|}{ Neonatal information } \\
\hline Mean length of stay (days \pm SD) & $54.6 \pm 46.9$ & $46.7 \pm 44.0$ & 0.128 \\
\hline No. with respiratory support (\%) & $54(67.5)$ & $4,155(63.2)$ & 0.485 \\
\hline Mean length of respiratory support (days \pm SD) & $25.3 \pm 27.4$ & $17.7 \pm 24.0$ & 0.022 \\
\hline No. with oxygen therapy (\%) & $49(61.3)$ & $3,426(52.1)$ & 0.115 \\
\hline Mean length of oxygen therapy (days \pm SD) & $28.3 \pm 35.1$ & $24.2 \pm 38.3$ & 0.462 \\
\hline No. with documented necrotizing enterocolitis (\%) & $4(5.0)$ & $226(3.4)$ & 0.358 \\
\hline No. with surgery for patent ductus arteriosus (\%) & $8(10.0)$ & $240(3.7)$ & 0.010 \\
\hline No. with documented sepsis (\%) & $14(17.5)$ & $951(14.5)$ & 0.425 \\
\hline
\end{tabular}

randomized, double-blind, clinical trial, and is more significant for infants of 32-35 weeks GA without BPD (80\% reduction over placebo, $p=0.002)$ compared to infants of $<32$ weeks GA (47\% reduction over placebo, $p=0.003$ ) [1]. While the use of prophylaxis has been adopted almost universally for infants of $<32$ weeks GA, there has been a guarded approach to RSV immunization in the 33-35 weeks GA cohort, despite the supportive scientific evidence. This is not surprising, because palivizumab is costly and this group comprises a significant proportion of annual births which has steadily climbed over recent years universally, given the increasing number of deliveries of late preterm infants. However, the use of specific risk factors weighted against the risk of RSV-positive hospitalization [10, 11] or validated risk models based on defined variables has streamlined a more conservative, cost-effective prophylaxis program for 33-35 weeks GA infants [12, 13, 35-37].

In our study, RSV-positive hospitalization rates for infants of both $\leq 32$ and 33-35 weeks GA following prophylaxis were similar at 1.5 and $1.4 \%$, respectively, and were lower than similar groups in the treated arm of the IMpact trial (5.8 and $1.8 \%$, respectively), despite a threefold greater sample size [1]. This real-world experience of the improved effectiveness of palivizumab was also noted in the United States Outcomes Registry, which realized higher hospitalization rates of $1.84 \%$ for infants of $<32$ weeks GA $(n=7,786)$ and lower rates of $0.83 \%$ for infants of $32-$ 35 weeks GA $(n=9,294)$, respectively, with significantly higher numbers of recruited infants who had similar gestational ages and pre-existing medical disorders such as CHD, BPD, and CF [38]. The risk scoring tool, or a modified version thereof, is used in all of the Canadian provinces to target RSV prophylaxis cost-effectively for 33-35 weeks GA infants who are considered to be at moderate to high risk (risk score 49-100) for RSV hospitalization [12]. This may account for the difference in RSV-positive hospitalization rates compared to the United States Outcomes Registry [38]. Of interest, the overall compliance in our study relative to the expected number of palivizumab doses and $30 \pm 5$ day dose intervals during the RSV season was higher at $92.6 \% \pm$ $27.9 \%$ versus 79.9 to $82.7 \%$ and 71.9 to $75.7 \%$ versus 65.2 to $69.5 \%$, respectively, in the United States Outcomes Registry, which may further explain some of the differences in the RSV-related hospitalization rates [38].

Several environmental and demographic risk factors are associated with severe RSV infection and subsequent 


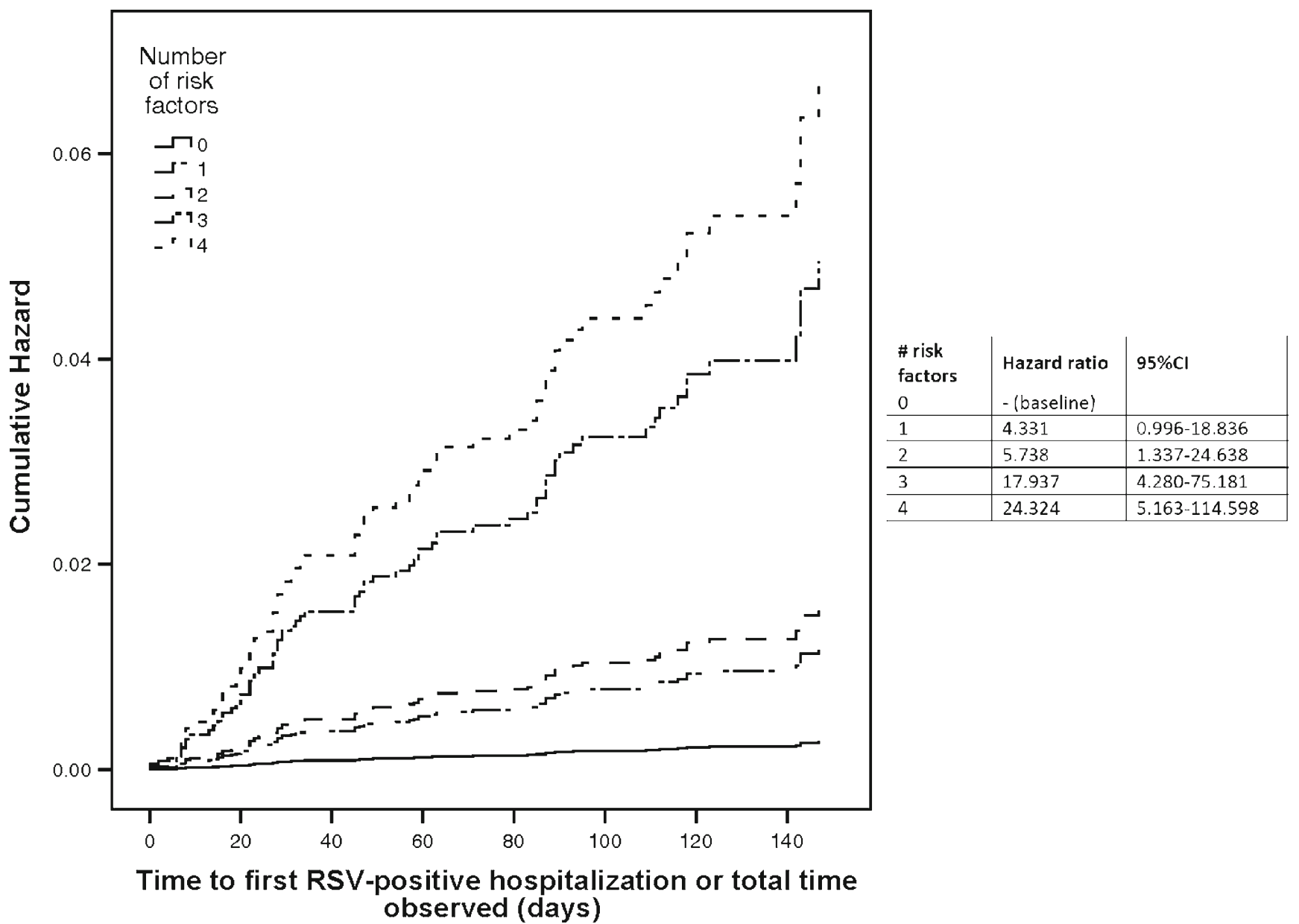

Fig. 2 Cox proportional hazard curves illustrating the number of risk factors that had a significant effect on the time to first RSV-positive hospitalization: having siblings, $>5$ individuals in the household, a history of atopy in the immediate family, and smoking in the household

hospitalization. These invariably include prematurity, sex, household crowding, daycare attendance, exposure to tobacco smoke and maternal smoking during pregnancy, young siblings, chronological age and birth early during the RSV season, intrauterine growth restriction, familial atopy and asthma, and short duration of breast feeding $[4,10,11,13$, 39-45]. We established that, in premature infants of $<35$ weeks GA who had received palivizumab, similar risk factors such as having siblings, $>5$ individuals in the household, a history of atopy in the immediate family, and smoking in the household also determined the time to first RSV hospitalization. The effect of each risk factor was independently significant and was augmented six-fold as the number of risk factors cumulatively rose from 1 to 4 in an individual patient. Our study confirms the relationship between environmental smoke exposure and RSV lower respiratory tract infection hospitalization, which is similar to other documented reports, but the effect is not uniformly consistent across published studies [46-48] because the association is likely related to the dose and concentration of circulating cigarette smoke extract $[49,50]$.
The limitations of our study include the absence of control groups for infants who received prophylaxis, which affected our ability to interpret the magnitude of the reduction in RSV hospitalization, apart from comparisons with historical controls from the IMpact study [1]. Subjects of 33-35 weeks GA and considered to be low risk (score 0-48) are not enrolled in the CARESS database and, therefore, we cannot draw any conclusions on the outcomes of this cohort. However, in a previous study involving 430 infants of 33-35 weeks GA, the low-risk group comprised $81 \%$ of the patients, of whom only $1.4 \%$ were hospitalized with an RSV infection [51].

In summary, this is the largest study that determined the outcomes of premature infants of $\leq 35$ completed weeks GA without underlying medical disorders who received prophylaxis in a single RSV season over four consecutive years. RSV hospitalizations were similar for infants of $\leq 32$ weeks GA and those between 33 and 35 weeks GA, despite the greater number of doses received by infants of $\leq 32$ weeks GA. The low hospitalization rate could be, in part, related to the high compliance achieved with infants receiving $92.6 \%$ of their expected number of injections and the higher 
efficacy of palivizumab, as demonstrated in the original randomized controlled trial [1]. RSV prophylaxis of infants of 33-35 weeks GA is both beneficial and cost-effective, but should be rationalized based on country-specific epidemiological data, local financial budgets and funding availability, and should be strategized to target the highest risk infants in this sub-population.

Acknowledgments The authors would like to thank the following investigators in the CARESS 2006-2011 seasons: Dr. Candice Bjornson (Alberta Children's Hospital), Dr. Georges Caouette [Centre Hospitalier de l'Université (CHU) Laval], Dr. Marc Lebel (CHU Sainte-Justine), Dr. Mario Eddy Dumas (CHU Sherbrooke), Dr. Charles Hui (Children's Hospital of Eastern Ontario), Dr. Ann Bayliss (Credit Valley Hospital), Dr. Bruno DiGravio (Grand River Hospital), Dr. Jean-Pierre Doray (Hôpital Charles LeMoyne), Dr. Dora Stinson (IWK Health Care), Dr. Apostolos Papageorgiou (Jewish General Hospital), Dr. Marianne Mitchell (Lakeridge Health Oshawa), Dr. Aaron Chiu (Manitoba Institute of Child Health), Dr. Bosco Paes (McMaster Children's Hospital), Dr. Roderick Canning (Moncton Hospital), Dr. Anne-Marie Canakis (Montreal Children's Hospital), Dr. Karel O’Brien (Mount Sinai Hospital), Dr. Karen Chang (Rouge Valley Hospital), Dr. Koravangattu Sankaran (Royal University Hospital), Dr. Vincent Ho (Royal Victoria Hospital), Dr. Upton Allen (Sick Kids Hospital), Dr. Larry Chang (Southlake Regional Health Centre), Dr. Cecil Ojah (St. John Regional Hospital), Dr. David Lee (St. Joseph's Health Care), Dr. Carina Majaesic (Stollery Children's Hospital), Dr. Marc Blayney (Sudbury Regional Hospital), Dr. Jelena Popovich (Toronto East General Hospital), Dr. Frank Jagdis (Victoria General Hospital), Dr. Ivor Margolis (William Osler Health Centre), Dr. Godfrey Bacheyie (Windsor Regional Hospital), and Dr. Brian Simmons (Women's College Hospital).

The authors would also like to thank all the nurses, coordinators, and families for their support, and Elyse Reim, Hadas Benhabib, Philip Francis, Niles Patel, and Tina Singal for their help with the data verification and input.

Conflict of interest statement B.P., I.M., and K.L.L. have received investigator-initiated research funding from Abbott Laboratories Limited and have been compensated as advisors and/or lecturers for Abbott and MedImmune. I.M. has received research grants from MedImmune, SIDS Calgary, Alberta Centre for Child, Family \& Community Research, and Alberta Law Foundation. A.L. has received a speaker's honorarium from Abbott.

Open Access This article is distributed under the terms of the Creative Commons Attribution License which permits any use, distribution, and reproduction in any medium, provided the original author(s) and the source are credited.

\section{References}

1. IMpact-RSV Study Group (1998) Palivizumab, a humanized respiratory syncytial virus monoclonal antibody, reduces hospitalization from respiratory syncytial virus infection in high-risk infants. The IMpact-RSV Study Group. Pediatrics 102(3 Pt 1):531-537

2. Committee on Infectious Diseases (2009) From the American Academy of Pediatrics: Policy statements-Modified recommendations for use of palivizumab for prevention of respiratory syncytial virus infections. Pediatrics 124:1694-1701

3. Deutsche Gesellschaft für Pädiatrische Infektiologie (DGPI); Deutsche Gesellschaft für Pädiatrische Kardiologie (DGPK); Gesellschaft für Pädiatrische Pneumologie (GPP); Gesellschaft für Neonatologie und
Pädiatrische Intensivmedizin (GNPI) (2006) Stellungnahme zur Prophylaxe von schweren RSV-Erkrankungen bei Risikokindern mit Palivizumab. http://www.dgpi.de/pdf/Leitlinie_Palivi zumab_270kt2006.pdf. Accessed January 2012

4. Figueras Aloy J, Carbonell Estrany X; Comité de Estándares de la Sociedad Española de Neonatología (2010) Recommendations for the use of palivizumab in the prevention of respiratory syncytial virus infection in late preterm infants (32(1) to 35(0) weeks of gestation). An Pediatr (Barc) 73(2):98.e1-98.e4

5. Figueras Aloy J, Quero J, Doménech E, López Herrera MC, Izquierdo I, Losada A, Perapch J, Sánchez-Luna M; Comité de Estándares de la Sociedad Española de Neonatología (2005) Recommendations for the prevention of respiratory syncytial virus infection. An Pediatr (Barc) 63(4):357-362

6. Resch B, Berger A, Bernert G, Eber E, Frischer T, Simma B, Zacharasiewicz A, Zach M (2008) Konsensuspapier zur prophylaxe der RSV-infektion mit palivizumab und post-RSVatemwegserkrankung. Monatsschr Kinderheilkd 156:381-383

7. Robinson JL; Canadian Paediatric Society, Infectious Diseases and Immunization Committee (2011) Preventing respiratory syncytial virus infections. Paediatr Child Health 16(8):488-490

8. Rondini G, Macagno F, Barberi I (2004) Raccomandazioni della Società Italiana di Neonatologia per la prevenzione delle malattie da virus respiratorio sinciziale (VRS). Acta Neonatologica 1:1-11

9. Carbonell-Estrany X, Simões EA, Fullarton JR, Ferdynus C, Gouyon JB; European RSV Risk Factor Study Group (2010) Validation of a model to predict hospitalization due to RSV of infants born at 3335 weeks' gestation. J Perinat Med 38(4):411-417

10. Figueras-Aloy J, Carbonell-Estrany X, Quero J; IRIS Study Group (2004) Case-control study of the risk factors linked to respiratory syncytial virus infection requiring hospitalization in premature infants born at a gestational age of 33-35 weeks in Spain. Pediatr Infect Dis J 23(9):815-820

11. Law BJ, Langley JM, Allen U, Paes B, Lee DS, Mitchell I, Sampalis J, Walti H, Robinson J, O’Brien K, Majaesic C, Caouette G, Frenette L, Le Saux N, Simmons B, Moisiuk S, Sankaran K, Ojah C, Singh AJ, Lebel MH, Bacheyie GS, Onyett H, Michaliszyn A, Manzi P, Parison D (2004) The Pediatric Investigators Collaborative Network on Infections in Canada study of predictors of hospitalization for respiratory syncytial virus infection for infants born at 33 through 35 completed weeks of gestation. Pediatr Infect Dis J 23(9):806-814

12. Sampalis JS, Langley J, Carbonell-Estrany X, Paes B, O'Brien K, Allen U, Mitchell I, Aloy JF, Pedraz C, Michaliszyn AF (2008) Development and validation of a risk scoring tool to predict respiratory syncytial virus hospitalization in premature infants born at 33 through 35 completed weeks of gestation. Med Decis Making 28(4):471-480

13. Simões EA, Carbonell-Estrany X, Fullarton JR, Liese JG, Figueras-Aloy J, Doering G, Guzman J; European RSV Risk Factor Study Group (2008) A predictive model for respiratory syncytial virus (RSV) hospitalisation of premature infants born at 33-35 weeks of gestational age, based on data from the Spanish FLIP Study. Respir Res 9:78

14. Simões EA, Carbonell-Estrany X, Fullarton JR, Rossi GA, Barberi I, Lanari M; European RSV Risk Factor Study Group (2011) European risk factors' model to predict hospitalization of premature infants born 33-35 weeks' gestational age with respiratory syncytial virus: validation with Italian data. J Matern Fetal Neonatal Med 24(1):152-157

15. Stensballe LG, Fullarton JR, Carbonell-Estrany X, Simões EA (2010) Population based external validation of a European predictive model for respiratory syncytial virus hospitalization of premature infants born 33 to 35 weeks of gestational age. Pediatr Infect Dis J 29(4):374-376

16. Horn SD, Smout RJ (2003) Effect of prematurity on respiratory syncytial virus hospital resource use and outcomes. J Pediatr 143(5 Suppl):S133-S141 
17. Law B, Macdonald N, Langley J, Mitchell I, Stephens D, Wang E, Robinson J, Boucher F, McDonald J, Dobson S (1998) Severe respiratory syncytial virus infection among otherwise healthy prematurely born infants: What are we trying to prevent? Paediatr Child Health 3(6):402-404

18. Willson DF, Landrigan CP, Horn SD, Smout RJ (2003) Complications in infants hospitalized for bronchiolitis or respiratory syncytial virus pneumonia. J Pediatr 143(5 Suppl):S142-S149

19. Mitchell I, Paes BA, Li A, Lanctôt KL; CARESS investigators (2011) CARESS: the Canadian registry of palivizumab. Pediatr Infect Dis J 30(8):651-655

20. Berner R, Schwoerer F, Schumacher RF, Meder M, Forster J (2001) Community and nosocomially acquired respiratory syncytial virus infection in a German paediatric hospital from 1988 to 1999. Eur J Pediatr 160(9):541-547

21. Boyce TG, Mellen BG, Mitchel EF Jr, Wright PF, Griffin MR (2000) Rates of hospitalization for respiratory syncytial virus infection among children in medicaid. J Pediatr 137(6):865-870

22. Meert K, Heidemann S, Abella B, Sarnaik A (1990) Does prematurity alter the course of respiratory syncytial virus infection? Crit Care Med 18(12):1357-1359

23. Stevens TP, Sinkin RA, Hall CB, Maniscalco WM, McConnochie KM (2000) Respiratory syncytial virus and premature infants born at 32 weeks' gestation or earlier: hospitalization and economic implications of prophylaxis. Arch Pediatr Adolesc Med 154 (1):55-61

24. Wang EE, Law BJ, Boucher FD, Stephens D, Robinson JL, Dobson S, Langley JM, McDonald J, MacDonald NE, Mitchell I (1996) Pediatric Investigators Collaborative Network on Infections in Canada (PICNIC) study of admission and management variation in patients hospitalized with respiratory syncytial viral lower respiratory tract infection. J Pediatr 129(3):390-395

25. Weigl JA, Puppe W, Schmitt HJ (2001) Incidence of respiratory syncytial virus-positive hospitalizations in Germany. Eur J Clin Microbiol Infect Dis 20(7):452-459

26. Heikkinen T, Valkonen H, Lehtonen L, Vainionpää R, Ruuskanen O (2005) Hospital admission of high risk infants for respiratory syncytial virus infection: implications for palivizumab prophylaxis. Arch Dis Child Fetal Neonatal Ed 90(1):F64-F68

27. Damore D, Mansbach JM, Clark S, Ramundo M, Camargo CA Jr (2008) Prospective multicenter bronchiolitis study: predicting intensive care unit admissions. Acad Emerg Med 15(10):887-894

28. Kneyber MC, Brandenburg AH, de Groot R, Joosten KF, Rothbarth PH, Ott A, Moll HA (1998) Risk factors for respiratory syncytial virus associated apnoea. Eur J Pediatr 157 (4):331-335

29. Ralston S, Hill V (2009) Incidence of apnea in infants hospitalized with respiratory syncytial virus bronchiolitis: a systematic review. J Pediatr 155(5):728-733

30. Schiller O, Levy I, Pollak U, Kadmon G, Nahum E, Schonfeld T (2011) Central apnoeas in infants with bronchiolitis admitted to the paediatric intensive care unit. Acta Paediatr 100(2):216-219

31. Sampalis JS (2003) Morbidity and mortality after RSV-associated hospitalizations among premature Canadian infants. J Pediatr 143 (5 Suppl):S150-S156

32. Méndez Rubio I, Lázaro de Mercado P, Carbonell Estrany X, Figueras Aloy J; Grupo IRIS (2010) Quality of life of preterm infants and admissions due to respiratory infections. An Pediatr (Barc) 73(3):121-131

33. Welliver RC Sr, Checchia PA, Bauman JH, Fernandes AW, Mahadevia PJ, Hall CB (2010) Fatality rates in published reports of RSV hospitalizations among high-risk and otherwise healthy children. Curr Med Res Opin 26(9):2175-2181

34. Holman RC, Shay DK, Curns AT, Lingappa JR, Anderson LJ (2003) Risk factors for bronchiolitis-associated deaths among infants in the United States. Pediatr Infect Dis J 22(6):483-490
35. Lanctôt KL, Masoud ST, Paes BA, Tarride JE, Chiu A, Hui C, Francis PL, Oh PI (2008) The cost-effectiveness of palivizumab for respiratory syncytial virus prophylaxis in premature infants with a gestational age of 32-35 weeks: a Canadian-based analysis. Curr Med Res Opin 24(11):3223-3237

36. Lázaro y de Mercado P, Figueras Aloy J, Doménech Martínez E, Echániz Urcelay I, Closa Monasterolo R, Wood Wood MA, Fitch Warner K (2006) The efficiency (cost-effectiveness) of palivizumab as prophylaxis against respiratory syncytial virus infection in premature infants with a gestational age of 32-35 weeks in Spain. An Pediatr (Barc) 65(4):316-324

37. Resch B, Sommer C, Nuijten MJ, Seidinger S, Walter E, Schoellbauer V, Mueller WD (2012) Cost-effectiveness of palivizumab for respiratory syncytial virus infection in high-risk children, based on long-term epidemiologic data from Austria. Pediatr Infect Dis J 31(1):e1-e8

38. Frogel M, Nerwen C, Cohen A, Vanveldhuisen P, Harrington M, Boron M; Palivizumab Outcomes Registry Group (2008) Prevention of hospitalization due to respiratory syncytial virus: results from the Palivizumab Outcomes Registry. J Perinatol 28(7):511-517

39. Langley GF, Anderson LJ (2011) Epidemiology and prevention of respiratory syncytial virus infections among infants and young children. Pediatr Infect Dis J 30(6):510-517

40. Simões EA (2003) Environmental and demographic risk factors for respiratory syncytial virus lower respiratory tract disease. J Pediatr 143(5 Suppl):S118-S126

41. Sommer C, Resch B, Simões EA (2011) Risk factors for severe respiratory syncytial virus lower respiratory tract infection. Open Microbiol J 5:144-154

42. Al-Shehri MA, Sadeq A, Quli K (2005) Bronchiolitis in Abha, Southwest Saudi Arabia: viral etiology and predictors for hospital admission. West Afr J Med 24(4):299-304

43. Carbonell-Estrany X, Quero J; IRIS Study Group (2001) Hospitalization rates for respiratory syncytial virus infection in premature infants born during two consecutive seasons. Pediatr Infect Dis J 20(9):874-879

44. von Linstow ML, Høgh M, Nordbø SA, Eugen-Olsen J, Koch A, Høgh B (2008) A community study of clinical traits and risk factors for human metapneumovirus and respiratory syncytial virus infection during the first year of life. Eur J Pediatr 167(10):1125-1133

45. Semple MG, Taylor-Robinson DC, Lane S, Smyth RL (2011) Household tobacco smoke and admission weight predict severe bronchiolitis in infants independent of deprivation: prospective cohort study. PLoS One 6(7):e22425

46. Holberg CJ, Wright AL, Martinez FD, Ray CG, Taussig LM, Lebowitz MD (1991) Risk factors for respiratory syncytial virusassociated lower respiratory illnesses in the first year of life. Am J Epidemiol 133(11):1135-1151

47. Liese JG, Grill E, Fischer B, Roeckl-Wiedmann I, Carr D, Belohradsky BH; Munich RSV Study Group (2003) Incidence and risk factors of respiratory syncytial virus-related hospitalizations in premature infants in Germany. Eur J Pediatr 162(4):230-236

48. Sritippayawan S, Prapphal N, Wong P, Tosukhowong P, Samransamruajkit R, Deerojanawong J (2006) Environmental tobacco smoke exposure and respiratory syncytial virus infection in young children hospitalized with acute lower respiratory tract infection. J Med Assoc Thai 89(12):2097-2103

49. Castro SM, Chakraborty K, Guerrero-Plata A (2011) Cigarette smoke suppresses TLR-7 stimulation in response to virus infection in plasmacytoid dendritic cells. Toxicol In Vitro 25(5):1106-1113

50. Modestou MA, Manzel LJ, El-Mahdy S, Look DC (2010) Inhibition of IFN-gamma-dependent antiviral airway epithelial defense by cigarette smoke. Respir Res 11:64

51. Paes B, Steele S, Janes M, Pinelli J (2009) Risk-Scoring Tool for respiratory syncytial virus prophylaxis in premature infants born at 33-35 completed weeks' gestational age in Canada. Curr Med Res Opin 25(7):1585-1591 